
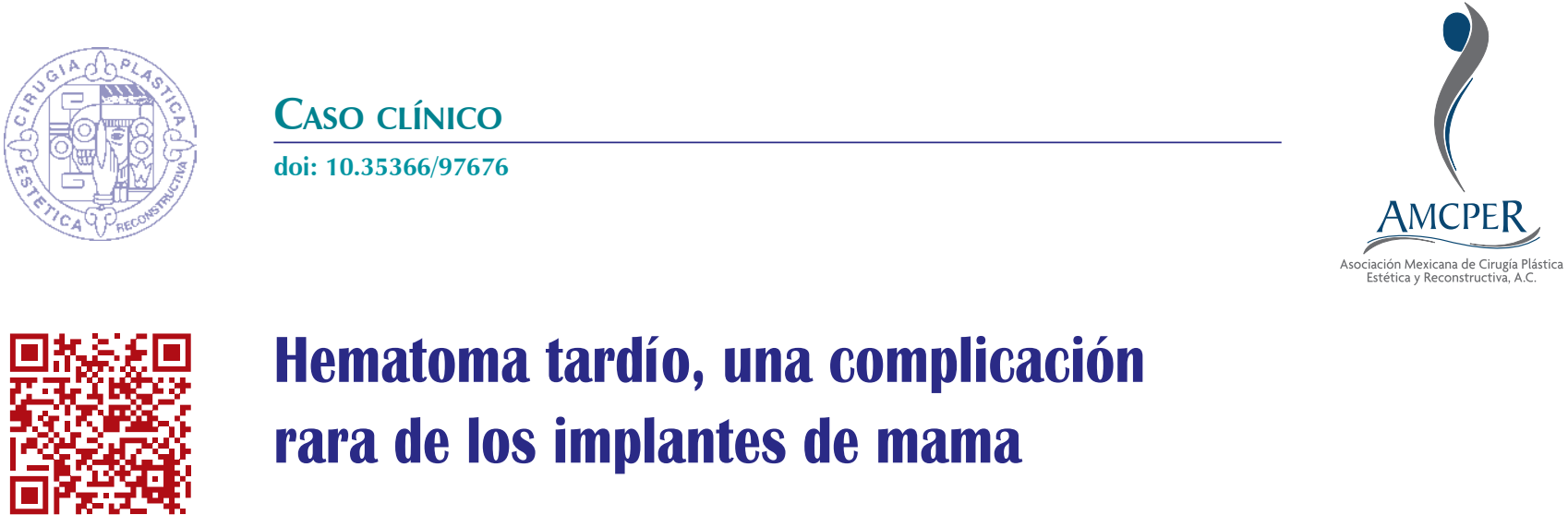

\title{
Hematoma tardío, una complicación rara de los implantes de mama
}

\author{
Late hematoma, a rare complication on breast implant \\ Dr. Luis Tamez-Pedroza,* Dr. Iram González-Vargas, ${ }^{\ddagger}$ \\ Dr. Francisco Palacios-Luna, ${ }^{\S}$ Dr. Mauricio Manuel García-Pérez
}

\begin{abstract}
Palabras clave: Implantes mamarios, hematoma tardío, tratamiento, capsulectomía, cambio de implantes.
\end{abstract}

Keywords: Breast implants, late hematoma, treatment, capsulectomy, implant change.

\footnotetext{
* Médico Residente de Cirugía General.

₹ Profesor del Servicio

Cirugía Plástica.

§ Médico Residente de

Cirugía Plástica.

ๆ Jefe del Servicio de

Cirugía Plástica.
}

Hospital Universitario «Dr. José Eleuterio González». Monterrey, N.L.

Recibido:

28 mayo 2020 Aceptado para publicar: 13 julio 2020

\section{RESUMEN}

El hematoma tardío es una complicación rara en el uso de implantes mamarios; no hay datos sobre su incidencia. Varios autores refieren diferentes teorías sobre su etiología, pero hasta hoy no existe alguna comprobada. Reportamos el caso de una paciente que presentó un hematoma tardío espontáneo. La paciente llegó al consultorio quejándose de aumento gradual de la mama izquierda en los últimos 15 días. Tratamos el hematoma con drenaje por punción guiado con ultrasonido con mejoría total de los síntomas. Una semana más tarde, regresó con los mismos síntomas y nuevamente se realiza drenaje guiado por ultrasonido y se decide programar la cirugía una semana después, drenaje, capsulectomía y reemplazo de implantes, con seguimiento a través de la consulta ambulatoria. Siete meses después no ha presentado recurrencia del hematoma.

\section{ABSTRACT}

Late hematoma is a rare complication in the use of breast implants; there are no data on its incidence. Several authors refer different theories about its etiology, but to this day none has been proven. We report the case of a patient who presented a spontaneous late hematoma. The patient came to the office complaining of gradual enlargement of the left breast in the previous 15 days. We treated the hematoma with ultrasound guided puncture drainage with overall improvement of the symptoms. A week later the patient returned with the same symptoms and again ultrasound guided drainage was performed and it was decided to schedule the surgical date one week later, involving drainage, capsulectomy, and implant replacement, with the patient follow-up provided through outpatient consultation. Seven months have gone by and she has not had a hematoma recurrence.

\section{INTRODUCCIÓN}

$\mathrm{E}^{\mathrm{I}}$ I hematoma agudo en la cirugía de implantes - mamarios se reporta como la tercera complicación más común después de la contractura capsular y ruptura. ${ }^{1} \mathrm{Su}$ incidencia se informa con una frecuencia del 2 al 10.3\% y generalmente ocurre en los primeros tres días. Hasta 2004, sólo se habían notificado 10 casos de hematomas mamarios tardíos. ${ }^{2}$ En enero de 2020 encontramos sólo 44 casos relacionados con hematoma espontáneo tardío en la Biblioteca Nacional de Medicina de EEUU, y en Institutos Nacionales de Salud (www.ncbi.nlm.nih.gov/pubmed) 39 relacionados con el aumento estético de las mamas y sólo cinco relacionados con cirugías reconstructivas. Exponemos un caso de presentación tardía de hematoma mamario secundario a implantes mamarios.

\section{CASO CLÍNICO}

Mujer de 50 años que se había sometido previamente a un aumento de mamas en 2017 con implantes mamarios lisos de silicón de $415 \mathrm{~mL}$. Dos años más tarde la paciente se presentó en el hospital refiriendo aumento progresivo de volumen y dolor de la mama izquierda. En los últimos

Citar como: Tamez-Pedroza L, González-Vargas I, Palacios-Luna F, García-Pérez MM. Hematoma tardío, una complicación rara de los implantes de mama. Cir Plast. 2020; 30 (2): 123-125. https://dx.doi.org/10.35366/97676 
15 días, negó algún antecedente de trauma o uso de anticoagulantes (Figuras 1 y 2). La persona fue enviada a ultrasonido mamario (US) (Figura 3) con reporte de implante mamario izquierdo con imágenes lineales móviles y ecogénicas en el interior sugestivas de rotura intracapsular asociada con una colección subcapsular de gran volumen que cubre los cuatro cuadrantes, heterogéneo, de predominio hipoecoico, sin flujo US Doppler.

La paciente fue tratada con aspiraciones por aguja percutánea, guiada por ultrasonido en dos ocasiones. En el primer intento se drenó $500 \mathrm{~mL}$; una semana después, en el segundo episodio, drenamos $300 \mathrm{~mL}$ y en este episodio se decidió junto con la paciente programar la extracción quirúrgica para mejorar los síntomas, misma que se realizó una semana después bajo anestesia general; drenamos $50 \mathrm{~mL}$ de hematoma, realizamos capsulectomía y reemplazo de implante mamario liso de $415 \mathrm{~mL}$ en el plano submuscular de las dos mamas, sin encontrar algún vaso sanguíneo con sangrado activo en el tejido capsular. No presentó complicaciones a los seis meses de seguimiento. El informe histopatológico de la cápsula mamaria izquierda (Figura 4) reportó cápsula fibrosa con proceso inflamatorio crónico severo (agregados linfoides no neoplásicos).

\section{DISCUSIÓN}

El hematoma tardío secundario a implantes mamarios es algo raro, con no más de 50 casos en la literatura. Algunas de las posibles etiologías reportadas de casos previos señalan que en 1979 Georgiade $^{3}$ notificó el primer caso de hematoma

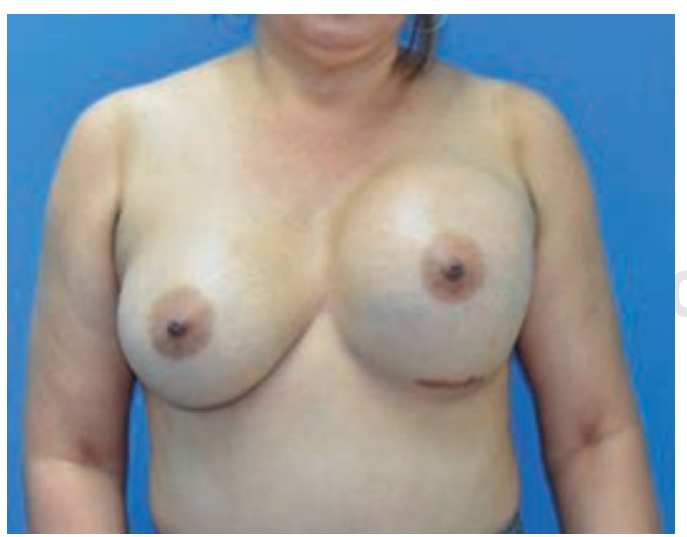

Figura 1: Paciente vista de frente.

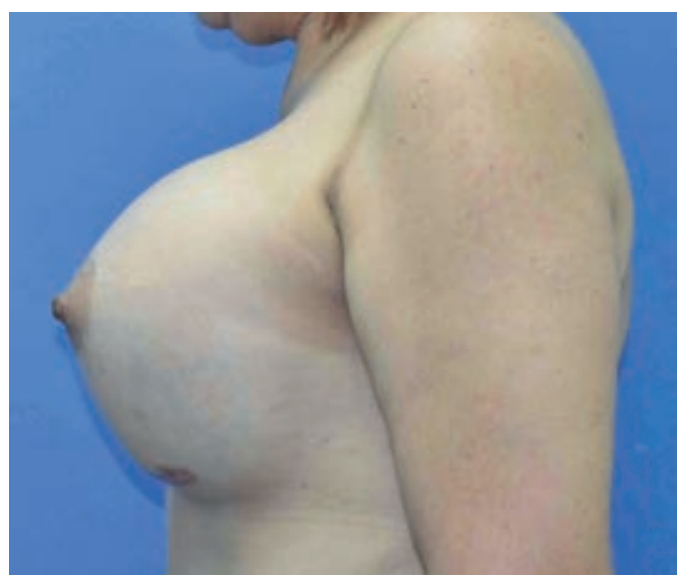

Figura 2: Vista lateral de la paciente.

tardío; reportó que la etiología estaba relacionada con el uso de esteroides en el implante, utilizaron prótesis expandibles de silicón, cada una con 40 mg de acetónido de triamcinolona y creen que una gran dosis de esteroides se asoció con la erosión tardía de la arteria de tamaño mediano. Marques ${ }^{4}$ reportó un caso de hematoma tardío después de un año y nueve meses, relacionado con un evento sugerente de actividad física moderada; atribuyó la etiología a las microfracturas en la cápsula. Seis años después, en 1998, Wang ${ }^{5}$ reportó dos casos de hematomas espontáneos después de cinco meses y tres años respectivamente; informaron que el recubrimiento de poliuretano desencadena una alta respuesta vascular e inflamatoria que puede causar el sangrado. Görgü ${ }^{6}$ reportó un caso con hematoma mamario tardío después de la actividad física, con antecedentes de trauma indirecto; pensó que el movimiento repentino entre la prótesis y la cápsula resultó en la ruptura de la arteria pericapsular. lorwerth ${ }^{7}$ informó el segundo periodo de tiempo más largo entre la cirugía de implante y el hematoma tardío: 12 años después, sin identificar algún factor etiológico. En 2005, Veiga ${ }^{8}$ informó un drenaje exitoso guiado por ultrasonido en un caso con recurrencia en tres ocasiones; en el tercer episodio, el equipo quirúrgico estaba listo para intervenir a la paciente, pero ésta ya no presentó recurrencia. Rijssen ${ }^{9}$ en 2008 reportó dos casos relacionados con apretón de mama durante la actividad sexual, fue el primer informe de caso en la literatura relacionado con esta etiología. El último informe fue el de Kim ${ }^{10}$ en 2018. 


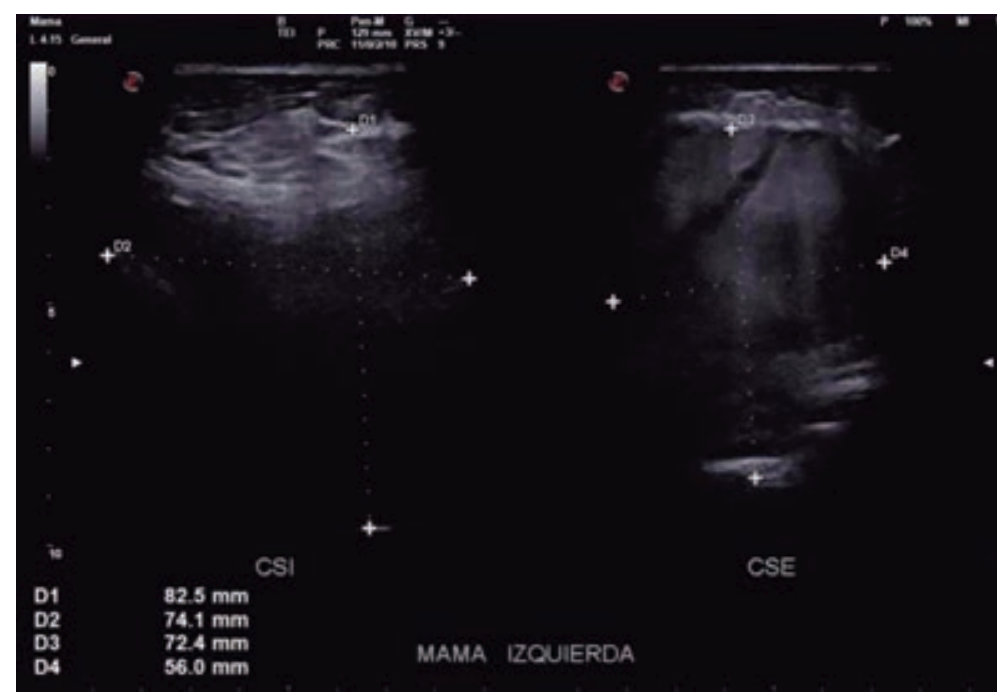

Figura 3: Ecografía mamaria en el primer episodio.

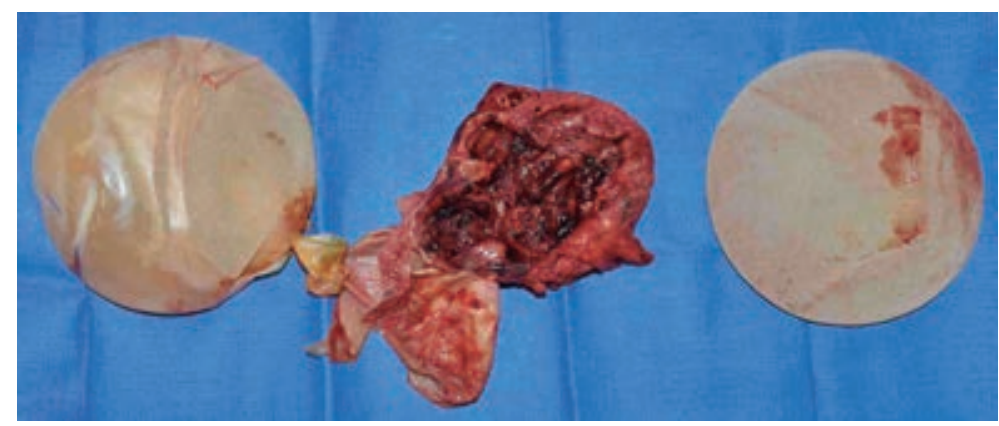

Figura 4: La cápsula mamaria izquierda obtenida al reemplazar el implante mamario. para esto, complicación que ocurrió en pacientes con implantes de 165 a 465 mL. Creemos que se debe investigar más sobre el tratamiento conservador en implantes colocados con menos de 10 años, para evaluar la efectividad del tratamiento conservador en hematomas tardíos en implantes mamarios, el tratamiento de elección y con mejores resultados parece ser el drenaje, capsulectomía y el reemplazo de implantes.

\section{REFERENCIAS}

1. Gabriel SE, Woods JE, O'Fallon M, Beard M, Kurland LT, Melton LJ. Complications Leading to Surgery after Breast Implantation. N Engl J Med 1997; 336: 677-682.

2. Brickman M, Parsa NN, Parsa FD. Late hematoma after breast implantation. Aesthet Plast Surg 2004; 28 : 80-82.

3. Georgiade NG, Serafin D, Barwick W. Late development of hematoma around a breast implant, necessitating removal. Plast Reconstr Surg 1979; 64 (5): 708-710.

4. Marques AF, Brenda E, Saldiva PH, Andrews J. Capsular hematoma as a late complication in breast reconstruction with silicone gel prostheses. Plast Reconstr Surg 1992; 89 (3): 543-545.

5. Wang BH, Chang BW, Sargeant R, Manson PN. Late capsular hematoma after breast reconstruction with polyurethane-covered implants. Plast Reconstr Surg 1998; 102 (2): 450-452.

6. Görgü M, Aslan G, Tuncel A, Erdogan B. Late and long-standing capsular hematoma after aesthetic breast augmentation with a saline-filled silicone prosthesis: A case report. Aesthetic Plast Surg 1999; 23 (6): 443-444.

7. Iorwerth A, Cochrane R, Webster DJ. Chronic haematoma as a late complication of cosmetic breast augmentation. Breast 2000; 9 (3): 158-160.

8. Veiga DF, Filho JV, Schnaider CS, Archangelo I Jr. Late hematoma after aesthetic breast augmentation with textured silicone prosthesis: a case report. Aesthetic Plast Surg 2005; 29 (5): 431-433; discussion 434.

9. van Rijssen $A L$, Wilmink $H$, van Wingerden JJ, van der Lei B. Amorous squeezing of the augmented breast may result in late capsular hematoma formation: A report of two cases (and a review of Englishlanguage literature on late hematoma formation in the augmented breast). Ann Plast Surg 2008; 60 (4): 375-378.

10. Kim L, Castel N, Parsa FD. Case of late hematoma after breast augmentation. Arch Plast Surg 2018; 45 (2): 177-179.

\section{Correspondencia: \\ Dr. Luis Tamez-Pedroza \\ Gonzalitos S/N, Col. Mitras Centro, 64460, Monterrey, N.L., México. \\ E-mail: Luis687@hotmail.com}

Conflicto de intereses: Los autores de este artículo no tienen conflicto de intereses que declarar. 